\title{
V. Comparative analysis of the urine of various animals
}

\section{Vauquelin}

To cite this article: M. Vauquelin (1813) V. Comparative analysis of the urine of various animals, Philosophical Magazine Series 1, 41:177, 17-20, DOI: 10.1080/14786441308638698

To link to this article: http://dx.doi.org/10.1080/14786441308638698

曲 Published online: 27 Jul 2009.

Submit your article to this journal ๘

Џ Article views: 3

Q View related articles ¿ 
lysed, presented all the characters of an animal matter. The liquid in a short tıme purefied. M. Moscati made the sane experiment in an hospital, by suspending the glass spheres over several sick persons: it was attended with the sane phromena and the same results. These experiments ought to be repeated and followed up: they might be varied, multiplied, and compared, with a view to elucidate the theory of icontagion which takes place withont immediate contact. In this way we might also examine the alteration which miasmata undergo, when the nitric or muriatic fumigations are resorted to.

V. Compurative Analysis of the Urine of various Animals. By $M$. Vauquelin*.

$T_{\text {HF nuly kinds of urine which chemists have hitherto }}$ analysed in a satisfactory nanner have been those of men, and some of the larger herbivorous animals.

The urines of carnivorous and wild animals have not as yet, so far as' I know, been examined by any person.

Nevertheles3, if we admit that comparative anatomy on the one hand has greatly contributed to the advancement of physiology, we shall perhaps also ascertain that comparative chemistry may, on the other hand, be made conducive to thit science.

Already has the urine of birds furnished results sufficiently interesting and unexpected to induce chemists to prosecute their experiments among all classes of animals which furnish this liquid, that they nay not in future entirely rely on analogy. With this view I have analysed the urine of the royal tiger, the lion, and the beaver; the results of which I subjoin, intending to extend my experiments to other animals.

The urines of the lion and tiger are perfectly similar: they have also some resemblance to that of man, but they differ in some essential points.

First difference: they are alkaline, even at the instant of being voided; the urine of a man in health is, on the contrary, always acid.

It is tn the presence of the ammonia developed in these urines that we ought to ascribe the strong and disagreeable mell, which they diffuse, even when in the act of issuing from the bladder of this class of animals.

* Annales de Chimee, tome lxxrii. p. 197.

Vol. 41. No, 177. Jan, 1813. 


\section{Comparative Analysis of the Urine of various Animals.}

Second difference : they do not contain any uric acid, nor any combination of this acid with the alkalis. At least, there was no sensible trace when the experiment was four times repeated.

The defect of uric acid in these urines was the more remarkable, as I used to ascribe its formation to animal food.

The third difference exhibited by the urine of the lion and the royal tiger from that of man, was the almost total absence of phosphate of lime.

This is what might be naturally expected, since this salt cannot be dissolved in water except by means of a superabundance of acid, and the urine in question is on the contrary alkaline.

It would nevertheless seem that the kidneys of these animals separate a certain quantity of this salt from the blood; for I found slight traces of it in these urines; and ammonia is formed in the bladder only, where probably it precipitates phosphate of lime: and this is without doubt the reason that the urime of these animals issues from the bladder almost always in a turbid state.

If according to this we ever find calculi in the bladders of these animals, they can be formed of phosphate of lime only, since this is the only insoluble substance they contain.

Fourtb difference: the urines of the lion and the tiger contain but an infinitely small quantity of muriate of soda; whereas that of men generally exhibits a great deal.

We find in these urines a great quantity of urea very much disposed to crystallization, and in general a little coloured; phosphates of soda and ammonia, sulphate of potasb, a mucnus matter, and a trace of iron.

The above are the points in which the urines of the lion and royal tiger resemble that of man; but they differ, as has been shown, in a sufficient number of points to warrant us in forming a particular species. It is composed as follows:

1. Urea.

2. Animal mucus.

3. Phosphate of soda.

4. Phosphate of ammonia.

5. Muriate of ammonia.

6. A trace of ptrosphaie of lime.

7. Sulphate of potash in a large quantity.

8. Au atom of muriate of soda.

trine of the Beaver.

A careful analysis screral times repeated of the urine of the 
the beaver, proved that it has a great resemblance to the urine of the common herbivorous animals.

In fact, we there find carbonate of lime kept in solution by a superabundance of carbonic acid: benzoic and acetic acids, urea, muriate of soda and sulphate of potash; and we meet with no uric acid in it, or phosphoric salts.

Nevertheless it differs in so far as it contains no muriate of ammonia, and as possessing a considerable quantity of carbonate and acetate of magnesia, which is not found, at least in a great quantity, in the urine of herbivorous animals.

I discovered the carbonate of magnesia in the following manner:

After having concentrated by a gentle heat a certain quantity of this urine, I decanted the liquor, and washed with distilled water the vessel to the sides of which the carbonate of lime adhered. I afterwards passed snlphuric acid into it diluted with water, "which produced a frothy effervescence on account of a mucous matter which carries off with it the carbonate of lime.

Perceiving that the sulphuric acid had acquired a bitter taste from this combination, I dried and calcined the mixture, then I washed it with a little water, and I obtained by the evaporation of the latter, a salt which had all the properties of sulphate of magnesia.

Wishing to ascertain by another experiment, if there was muriate of ammonia in the urine of the beaver, as well as in that of other herbivorous animals, 1 put into a portion of this thickened liquor a piece of caustic potash; and as the odour of the anmonia was not perceived even with the aid of heat, I concluded that it did not contain any muriate of ammonia: but a phanomenon was exhibited which astonished me, and which excited a desire to examine the cause of it. The liquor went into a gelatinouslike mass : suspecting that this effect was produced by the precipitation of some earthy substance, I treated the whole of the thickened urine which $I$ possessed with caustic potash; I filtered the liquor in order to obtain the matter in question; and after having washed and calcined it, I combined it with sulphuric acid diluted with water, and obtained sulphate of magnesia mixed with a little sulphate of lime.

Although I bave announced that the urine of the beaver contains acetare of magnesia, yet I am not perfeclly certain of it: in fact, it may be possible that during the evaporation, although effected with a gentle heat, a certain B 2 quantity 
quantity of acetic acid may be formed, and the latter may have acted on the carbonate of magnesia left in the liquor, on account of its solubility being greater than that of the carbonate of lime.

We generally ascertain by the colour, smell and taste, and above all by the property wiich the urine of the beaver possesses of staining alumed cloths, the kind of vegetables on which the animal feeds.

In the urine of the animal which I made the subject of my experiment, I distinguished evident marks of the colouring matter of willow bark, and its keeper confirmed the observation.

There seem to be cases, therefore, in which certain vegetable substances may pass through the digestive organs, and the circulation, without entirely losing the properties which distinguish them in their natural state.

I also found in the urine of the beaver a quantity of iron, which at first astonished me; but having reflected that it had been collected in a tinned iron vessel, and that it contained carbonic acid, I thought that the greater quantity of this metal proceeded from the vessel.

The urine of the beaver is therefore composed of,

1. Urea.

2. Animal mucus.

3. Benzoate of potash.

4. Carbonate of lime and magnesia.

5. Acetate of magnesia (doubtful).

6. Sulphate of potash.

7. Muriate of potash or of soda.

8. Vegetable colouring matter.

9. Lastly, a little iron.

VI. Observations on the Measurement of three Degrees of the Meridian conducted in England by Lieut.-Colonel William Mudge. By Don Joseph Rodriguez. Communicated by Joseph DB Mendoza Rios, Esq. F.R.S.*

The determination of the figure and magnitude of the earth has at all times excited the curiosity of mankind, and the history of the several attempts made by astronomers to solve this problem might be traced to the most remote antiquity. But the details of the methods pursued by the ancients on this subject being extremely vague, and their

* From the Philosophical Transactions for 1812, part ii. 